\title{
Reduced Venous Blood Basophil Count and Anxious Depression in Patients with Major Depressive Disorder
}

\author{
Ji Hyun Baek ${ }^{1,2}$, Hee-Jin Kim³ ${ }^{3}$ Maurizio Fava ${ }^{4}$, David Mischoulon ${ }^{4}$, George I Papakostas ${ }^{4}$, \\ Andrew Nierenberg ${ }^{4,5}$, Jung-Yoon Heo ${ }^{1}$, and Hong Jin Jeon ${ }^{1,4,5} \bowtie$ \\ 'Department of Psychiatry, Depression Center, Samsung Medical Center, Sungkyunkwan University School of Medicine, Seoul, Republic of Korea \\ 2Bipolar Clinic and Research Program, Massachusetts General Hospital, Harvard Medical School, Boston, USA \\ ${ }^{3}$ Department of Laboratory Medicine \& Genetics, Samsung Medical Center, Sungkyunkwan University School of Medicine, Seoul, Republic of Korea \\ ${ }^{4}$ Depression Clinical and Research Program, Massachusetts General Hospital, Harvard Medical School, Boston, USA \\ ${ }^{5}$ Departments of Health Sciences \& Technology, Management \& Research, Clinical Research Design \& Evaluation, Samsung Advanced Institute for \\ Health Sciences \& Technology (SAIHST), Seoul, Republic of Korea
}

Objective Anxious depression has a distinct neurobiology, clinical course and treatment response from non-anxious depression. Role of inflammation in anxious depression has not been examined. As an exploratory study to characterize the role of inflammation on a development of anxious depression, we aimed to determine the relationship between white blood cell (WBC) subset counts and anxiety in individuals with major depressive disorder (MDD).

Methods A total of 709 patients who were newly diagnosed with MDD were recruited. Anxiety levels of participants were evaluated using the Anxiety/ Somatization subitem of the Hamilton Depression Rating Scale. The association between WBC subset fraction and anxiety was evaluated.

Results Basophil and eosinophil sub-fractions showed significant negative correlations with HAM-D anxiety/somatization factor scores (basophils: $\mathrm{r}=-0.092, \mathrm{p}=0.014$ and eosinophils: $\mathrm{r}=-0.075, \mathrm{p}=0.046$ ). When an anxiety score (a sum of somatic and psychic anxiety) was entered as a dependent variable, only basophils showed significant negative association with the anxiety scores after adjusting for all other WBC subset counts and demographic factors $(\mathrm{t}=-2.57, \mathrm{p}=0.010)$.

Conclusion This study showed that anxious depression had a decreased basophil subfraction, which might be associated with involvement of inflammation in development of anxious depression.

Psychiatry Investig 2016;13(3):321-326

Key Words Anxious depression, Basophil, Inflammation.

\section{INTRODUCTION}

Anxious depression is a subtype of depression that is well known to have different neurobiological characteristics. ${ }^{1}$ Anxious depression generally shows poorer clinical course ${ }^{2}$ and treatment response, ${ }^{3,4}$ and higher suicide risk ${ }^{2,5}$ than non-anxious depression.

Chronic systemic inflammation is increasingly considered one of the important biological mechanisms of depression.

Received: May 14, 2015 Revised: August 23, 2015

Accepted: August 23, 2015 Available online: January 8, 2016

$\triangle$ Correspondence: Hong Jin Jeon, $\mathrm{MD}, \mathrm{PhD}$

Department of Psychiatry, Depression Center, Samsung Medical Center, Sungkyunkwan University School of Medicine, 81 Irwon-ro, Gangnam-gu, Seoul 06351, Republic of Korea

Tel: +82-2-3410-3586, Fax: +82-2-3410-0050, E-mail: jeonhj@skku.edu

(a) This is an Open Access article distributed under the terms of the Creative Commons Attribution Non-Commercial License (http://creativecommons.org/licenses/bync/3.0) which permits unrestricted non-commercial use, distribution, and reproduction in any medium, provided the original work is properly cited.
Immune system alteration in depression has been consistently documented. Several studies have reported an alteration in white blood cell (WBC) subset counts ${ }^{6-8}$ and increased proinflammatory cytokines, including IL- 6 and TNF- $\alpha$, in individuals with depression. ${ }^{9}$ Recent studies showed that a high inflammatory state can induce de novo depression, ${ }^{10}$ and cytokine infusion induces depression-like symptoms in humans. ${ }^{11}$ Furthermore, anti-inflammatory agents seem to have a beneficial effect on depression, ${ }^{12}$ and increased inflammation can worsen prognosis. ${ }^{13}$

Previous studies on the inflammatory system in depression have mainly focused on pro-inflammatory cytokines, including IL- 6 and TNF- $\alpha$. WBC subset fraction and counts also provide indirect evidence of an altered inflammatory system in anxious depression. A few reports suggested that severe depression is accompanied by disturbances in total white blood cell counts (i.e., leukocytosis) and leukocyte subset (i.e., neu- 
trophilia, monocytosis, lymphopenia) counts. ${ }^{6,7}$

Each WBC subset plays a different role in inflammation. Neutrophils are an essential part of the innate immune system and play a major role as phagocytes in acute bacterial or viral inflammation. Lymphocytes comprise 3 different immune cells, i.e., natural killer (NK) cells, T cell, and B cell and mainly work in recruiting humoral immune responses. Eosinophils are mainly associated with parasitic infection and allergic reaction. Basophils are mainly involved in hypersensitivity and anaphylactic reaction. Monocytes also function as phagocytes, but live longer than neutrophils.

Given that anxious depression is associated with a chronic course and poor response to treatment, the altered immune system might be one of the important factors that explain treatment resistance in anxious depression. However, altered blood cell counts in anxious depression have not been previously investigated.

In this exploratory study examining the immune systems in anxious depression, we aimed to characterize the relationship between WBC subset counts and anxiety, in individuals with major depressive disorder (MDD).

\section{METHODS}

\section{Subjects}

A total of 709 patients newly diagnosed with MDD by the diagnostic criteria of the DSM-IV, were recruited from the outpatient clinic of the Department of Psychiatry and Depression Center of the Samsung Medical Center between July 1, 2009 and July 28, 2012. We only included medically stable subjects who did not require any acute medical interventions. Those who had other axis I psychiatric disorders, including organic mental disorders, mental retardation, neurologic illness including epilepsy, and serious medical illnesses were excluded. Subjects were allowed to take regular mediations to treat non-severe chronic medical conditions including hypertension, diabetes and dyslipidemia as well as psychiatric conditions.

Detailed recruitment and evaluation procedures were described elsewhere. ${ }^{14}$ Briefly, psychiatrists with $>3$ years of clinical experience evaluated the participants' psychiatric and medical histories, and confirmed their eligibility. A trained psychologist blinded to the psychiatrists' judgment separately explored the participants' psychiatric diagnoses and current mood states. Subjects' diagnoses were evaluated using the Korean version of the Mini International Neuropsychiatric Interview's (MINI). ${ }^{15}$ Cohen's kappa values, a measure of the interrater reliability, have ranged from 0.22 to 0.93 in the Korean version of the MINI. ${ }^{16}$ The severity of depression was measured with the HAM-D. The MDQ and the HCL-32 were used for evaluating potential bipolarity. All study procedures were approved by the Institutional Review Board of the Samsung Medical Center.

\section{Measure of anxiety}

Levels of anxiety was measured using the Anxiety/ Somatization subitem of the Hamilton Depression Rating Scale (HAM-D). ${ }^{17}$ The Anxiety/Somatization factor of the HAM-D includes the following 6 items: anxiety (psychic), anxiety (somatic), somatic symptoms (gastrointestinal), somatic symptoms (general), hypochondriasis, and insight. Previous studies have used the sum of the anxiety/somatization factor score $\geq 7$ as the cut-off score for anxious depression. ${ }^{18}$ We regarded anxiety as either a dichotomous variable (i.e., presence of anxious depression) using the definition of anxious depression, or a continuous variable using the HAM-D anxiety/somatization factor total score, or individual item scores. (i.e., psychological anxiety, physical anxiety, gastrointestinal somatic symptoms, general somatic symptoms, hypochondriasis and insight).

\section{Blood sample collection and testing}

Peripheral blood samples were drawn into EDTA-anticoagulated vacutainer tubes. Complete cell counts were performed on the Sysmex XE2100 automated hematology analyzer (Sysmex Corporation, Kobe, Japan) within 4 hours of collection. The instrument generates differential counts of white blood cells by using multichannel analyses. Specifically, basophils are differentially counted from other granulocytes in a basophil channel by forward and side scattered light information based on their nature of resistance to acidic stripping of the cytoplasm by a specific lysing reagent.

\section{Statistical analysis}

The demographic data and blood cell counts were compared between individuals with anxious depression and nonanxious depression. Parametric variables were compared by the Student's t-test. Categorical data were analyzed by the chisquare test.

We used 3 different approaches to determine associations between WBC subsets and anxiety in depression. First, we regarded anxiety as a continuous variable, and performed correlation analyses with each WBC subset. Each item and the sum of the anxiety/somatization factors of the HAM-D were used as variables. Pearson's correlation analyses were done to determine the relationship between anxiety and WBC subset fractions. Second, we defined anxious depression as a HAM$\mathrm{D}$ anxiety/somatization factor score $\geq 7 .{ }^{18}$ Analysis of Covariance (ANCOVA) was performed to compare WBC subset fractions between individuals with anxious and non-anxious depression, after adjusting for age, sex and duration of educa- 
tion. Third, we performed linear regression analyses and logistic regression analyses to determine the effects of WBC subset counts on anxiety. We used raw counts of each subset in regression models, in order to include various WBC subsets in one model. Age and sex were additionally entered as covariates.

The null hypothesis was rejected at $\mathrm{p}<0.05$. The SPSS 17.0. statistical package was used for the analyses

\section{RESULTS}

Of the 709 individuals with MDD, 302 (42.6\%) were classified as having anxious depression. There were no significant differences in socio-demographic characteristics between individual with anxious and non-anxious depression (Table 1).

As expected, subjects with anxious depression had higher total HAM-D scores compared to those with non-anxious depression. Individuals with anxious depression showed a significantly higher percentage of segmented neutrophils and lower percentage of basophils as compared to those with nonanxious depression (Table 2). No other differences in cell counts were detected between the 2 groups.

The correlation analysis (Table 3 ) indicated that eosinophil and basophil counts were negatively correlated with HAM-D anxiety/somatization factor scores (eosinophil: $\mathrm{r}=-0.075, \mathrm{p}=$ 0.046; basophil: $\mathrm{r}=-0.092, \mathrm{p}=0.014$ ). The individual items of HAM-D anxiety/somatization factors i.e., psychological anxiety, somatic complaints and hypochondriasis also showed significant negative correlation with eosinophil counts; psychological anxiety showed significant negative correlation with the basophil count. Total HAM-D scores did not show any significant association with blood cell counts.

ANCOVA analyses revealed that individuals with anxious depression had lower percentages of basophils and lymphocytes, and a higher percentage of segmented neutrophils compared to those with non-anxious depression after adjusting for age, sex and duration of education.

When the HAM-D anxiety/somatization sum scores were used as a dependent variable in a linear regression model, the model was not statistically significant $(F=1.79$; $p=0.086)$. Logistic regression analysis using the presence of anxious depression as a dependent variable indicated that the model was not statistically significant $\left(\chi^{2}=12.26 ; p=0.092\right)$. However, when an anxiety score (a sum of somatic and psychic anxiety) was entered as a dependent variable, the model was statistically significant $(\mathrm{F}=2.16 ; \mathrm{p}=0.036)$, and basophil counts

Table 1. Socio-demographic characteristics of the subjects with major depressive disorder $(\mathrm{N}=709)$

\begin{tabular}{lcccc}
\hline \multirow{2}{*}{ Variables } & Individuals with anxious & Individuals with non-anxious & \multicolumn{2}{c}{ Statistics } \\
\cline { 3 - 5 } & depression $(\mathrm{N}=302)$ & $\mathrm{t}$ or $\chi^{2}$ & $\mathrm{p}$ \\
\hline Age & $47.0(15.3)$ & $46.1(16.6)$ & $\mathrm{t}=-0.75$ & 0.45 \\
Sex & $216(71.5)$ & $274(67.3)$ & $\chi^{2}=1.43$ & 0.23 \\
Duration of education & $12.6(4.1)$ & $12.8(3.8)$ & $\mathrm{t}=0.64$ & 0.52 \\
Currently married & $168(55.6)$ & $202(49.6)$ & $\chi^{2}=4.51$ & 0.21 \\
Currently employed & $256(84.8)$ & $347(85.3)$ & $\chi^{2}=8.57$ & 0.13 \\
HAM-D total score & $19.7(4.3)$ & $12.5(5.2)$ & $\mathrm{t}=-20.07$ & $<0.001$ \\
HAM-D anxiety/somatic factor score & $7.96(1.12)$ & $4.47(1.47)$ & $\mathrm{t}=-34.47$ & $<0.001$ \\
\hline
\end{tabular}

Anxiety/somatization factor score of the HAM-D $\geq 7$ as cut-off score for anxious depression. HAM-D: Hamilton depression rating scale

Table 2. Peripheral blood cell counts of the subjects with major depressive disorder $(\mathrm{N}=709)$

\begin{tabular}{|c|c|c|c|c|}
\hline \multirow{2}{*}{ Cell counts } & \multirow{2}{*}{$\begin{array}{l}\text { Individuals with anxious } \\
\text { depression }(\mathrm{N}=302)\end{array}$} & \multirow{2}{*}{$\begin{array}{l}\text { Individuals with non-anxious } \\
\text { depression }(\mathrm{N}=407)\end{array}$} & \multicolumn{2}{|c|}{ Statistics } \\
\hline & & & t or $\chi^{2}$ & $\mathrm{p}$ \\
\hline RBC counts & $4.50(0.47)$ & $4.51(0.47)$ & 0.50 & 0.62 \\
\hline WBC counts & $6.47(1.68)$ & $6.37(1.77)$ & -0.73 & 0.46 \\
\hline Platelet counts & $241.01(58.26)$ & $247.71(59.06)$ & -1.50 & 0.13 \\
\hline \multicolumn{5}{|l|}{ WBC subset (\%) } \\
\hline Segmented neutrophil & $58.64(9.61)$ & $57.12(9.80)$ & -2.07 & 0.04 \\
\hline Eosinophil & $2.08(2.04)$ & $2.28(2.15)$ & 1.29 & 0.20 \\
\hline Basophil & $0.40(0.26)$ & $0.47(0.31)$ & 3.11 & 0.002 \\
\hline Lymphocyte & $32.38(8.73)$ & $33.61(8.70)$ & 1.87 & 0.062 \\
\hline Monocyte & $6.50(2.00)$ & $6.51(2.19)$ & 0.086 & 0.93 \\
\hline
\end{tabular}

RBC: red blood cell, WBC: white blood cell 
showed a negative association with the anxiety scores, after adjusting for all other WBC subset counts and demographic factors $(\mathrm{t}=-2.57 ; \mathrm{p}=0.010)$ (Table 4).

\section{DISCUSSION}

This is the first study to investigate the relationship between basophil counts and the presence of co-morbid anxiety in MDD patients. We demonstrated differences in WBC subset fractions between anxious and non-anxious depression. Especially, analyses conducted showed that venous blood basophil counts were reduced in anxious depression vs. nonanxious depression. In fact, we found that such counts were inversely associated with anxiety severity, as measured by the anxiety/somatization subscaleof the HAM-D. Fractions of segmented neutrophils and lymphocytes also showed significant differences between anxious and non-anxious depression after adjusting for demographic factors.

Basophils are circulating blood granulocytes that comprise roughly $0.1-0.3 \%$ of all circulating WBCs. Basophils have abundant immunoglobulin $\mathrm{E}$ (IgE) receptors and histamine, and are mainly involved in mediating allergic reactions, including hypersensitivity reactions and anaphylaxis. Such re- actions involve the release of histamine and major proinflammatory cytokines, including IL-6, on activation. ${ }^{19}$ In addition, basophils share a hematopoitetic lineage with tissue-dwelling mast cells, which also play an important role in the inflammatory reaction. For instance, both basophils and mast cells contain abundant heparin and histamine. ${ }^{20}$ Interestingly enough, allergic diseases, such as atopic dermatitis and asthma, are known to be associated with depression. ${ }^{21,22}$ Psychological stress can activate the hypothalamic-pituitary-adrenal axis ${ }^{23}$ and the sympathoadrenal medullary system. ${ }^{24}$ Catecholamines and cortisol generated by both activated systems increase allergic inflammatory responses. ${ }^{25}$ Nerve terminals in cutaneous sensory nerves release neuropeptides, ${ }^{26}$ which eventually activate mast cells, which further release proinflammatory mediators. ${ }^{27}$ Interestingly, the mast cell is known to play a major role in the central nervous system (CNS) neuroinflammation. ${ }^{28}$

Basophils mainly release histamine in allergic reactions. The histamine system plays an important role in modulating alertness, anxiety, memory and mood. ${ }^{29}$ Mirtazapine and tricyclic antidepressants act on the histamine receptor directly, and are effective in decreasing anxiety. ${ }^{30} \mathrm{~A}$ recent animal study showed that histamine was released from the brain mast cell. ${ }^{31}$ Altera-

Table 3. Correlation analysis between peripheral blood cell counts and anxiety evaluated using HAM-D

\begin{tabular}{|c|c|c|c|c|c|c|c|c|}
\hline & Total WBC & Eosinophil & Basophil & Neutophil & Lymphocyte & Monocyte & $\mathrm{RBC}$ & Platelet \\
\hline HAM-D total score & 0.005 & 0.002 & -0.071 & 0.043 & -0.046 & -0.001 & -0.001 & $0.074^{*}$ \\
\hline $\begin{array}{l}\text { HAM-D anxiety/somatization } \\
\text { factor score }\end{array}$ & -0.010 & $-0.075^{*}$ & $-0.092^{*}$ & 0.046 & -0.035 & 0.022 & -0.031 & 0.037 \\
\hline \multicolumn{9}{|l|}{ HAM-D sub-item scores } \\
\hline Psychic anxiety & 0.009 & $-0.099^{* *}$ & $-0.122^{* *}$ & $0.086^{*}$ & -0.059 & -0.041 & -0.001 & 0.061 \\
\hline Somatic anxiety & 0.022 & 0.018 & -0.056 & -0.014 & 0.015 & -0.008 & $<0.001$ & 0.038 \\
\hline Somatic complaints & $<0.001$ & $-0.093^{*}$ & -0.027 & $0.109^{* *}$ & $-0.084^{*}$ & -0.058 & -0.059 & 0.041 \\
\hline General somatic symptoms & 0.008 & 0.065 & -0.054 & 0.017 & -0.033 & -0.002 & 0.007 & 0.067 \\
\hline Hypochondriasis & -0.066 & $-0.118^{* *}$ & -0.022 & 0.002 & 0.001 & $0.104^{* *}$ & -0.036 & -0.040 \\
\hline Insight & -0.013 & 0.035 & -0.009 & -0.055 & 0.039 & 0.057 & -0.017 & -0.029 \\
\hline
\end{tabular}

Pearson's correlation coefficients were presented. ${ }^{*} \mathrm{p}<0.05,{ }^{* *} \mathrm{p}<0.01$. HAM-D: Hamilton Depression Rating Scale, WBC: white blood cell, RBC: red blood cell

Table 4. Linear regression analysis with the HAM-D anxiety scores (sum of psychic anxiety and somatic anxiety) as a dependent variable

\begin{tabular}{|c|c|c|c|c|c|}
\hline & B & Standard error & Standardized $\beta$ & $\mathrm{t}$ & $\mathrm{p}$ \\
\hline Age & -0.005 & 0.003 & -0.064 & -1.69 & 0.091 \\
\hline Sex & -0.173 & 0.103 & -0.065 & -1.68 & 0.093 \\
\hline Eosinophil & -0.336 & 0.333 & -0.041 & -1.02 & 0.31 \\
\hline Basophil & -7.170 & 2.794 & -0.100 & -2.57 & 0.010 \\
\hline Neutrophil & 0.022 & 0.038 & 0.025 & 0.59 & 0.55 \\
\hline Lymphocyte & 0.020 & 0.078 & 0.010 & 0.26 & 0.80 \\
\hline Monocylte & 0.208 & 0.351 & 0.027 & 0.60 & 0.55 \\
\hline
\end{tabular}

Each white blood cell subset was entered using raw count. HAM-D: the Hamilton Depression Rating Scale 
tion in the histaminergic system may be involved in the development of anxious depression which may be associated with poor clinical course. Findings from our study may reflect the association between inflammation related to allergic reaction and anxious depression. Decreased basophil counts could affect histamine release and eventually increase the individuals' anxiety level. Further study of associated neuroinflammatory substances is required to confirm our findings.

In addition to decreased basophils, individuals with anxious depression in our study showed an increased percentage of segmented neutrophils. Maes et al. ${ }^{6}$ in a study on WBC counts and depression, reported monocytosis and neutrophilia in individuals with depression compared to healthy individuals; while McAdams and Leonard ${ }^{7}$ reported increased neutrophils and decreased monocytes. Increased cellular immunity may also be involved in poor clinical course and treatment responses.

Our findings need to be interpreted within the context of the study design. First, this was a cross-sectional study and WBC subset counts were evaluated only once. Second, we could not get detailed medical history, including current medication or certain medical conditions that may have affected the variation in WBC subset counts. We excluded all subjects who required acute medical intervention, including morbid obesity, in order to minimize the confounding effect of the subjects' medical condition. Third, peripheral WBC subset counts may not reflect the central inflammatory system. Fourth, we did not include non-depressed, healthy subjects in our study samples.

Despite these limitations, this study showed that there were differences in the basophil fraction and count between anxious and non-anxious depression. Basophils are associated with allergic reactions, the latter of which is also biologically associated with anxiety and depression. Further studies are required to confirm the findings from this work.

\section{Acknowledgments}

This research was supported by the Basic Science Research Program through the National Research Foundation of Korea (NRF) funded by the Ministry of Education, Science and Technology (No. 2011-0013064). This study was also supported by the Samsung Medical Center Clinical Research Development Program (CRDP) Grant SMO1131461 and Institute for Information \& communications Technology Promotion (IITP) grant funded by the Korea government (MSIP) (No. B0132-15-1003, the development of skin adhesive patches for the monitoring and prediction of mental disorders).

Funding for this study was provided by the National Research Foundation of Korea (NRF) and the Samsung Medical Center Clinical Research Development Program (CRDP) Grant. They had no further role in study design; in the collection, analysis and interpretation of data; in the writing of the report; and in the decision to submit the paper for publication.

\section{Conflicts of interest}

Dr. Fava has received research support from Abbott Laboratories, Alkermes, Aspect Medical Systems, Astra-Zeneca, BioResearch, BrainCells, Inc.,
Bristol-Myers Squibb Company, Cephalon, Clinical Trial Solutions, LLC, Eli Lilly \& Company, EnVivo Pharmaceuticals, Inc., Forest Pharmaceuticals Inc., Ganeden, GlaxoSmithKline, J \& J Pharmaceuticals, LichtwerPharma GmbH, Lorex Pharmaceuticals, NARSAD, NCCAM, NIDA, NIMH, Novartis, Organon Inc., PamLab, LLC, Pfizer Inc, Pharmavite, Roche, Sanofi-Aventis, Shire, Solvay Pharmaceuticals, Inc., Synthelabo, and Wyeth-Ayerst Laboratories. He has served as an advisor and consultant to Abbott Laboratories, Affectis Pharmaceuticals AG, Amarin, Aspect Medical Systems, Astra-Zeneca, Auspex Pharmaceuticals, Bayer AG, Best Practice Project Management, Inc, BioMarin Pharmaceuticals, Inc., Biovail Pharmaceuticals, Inc., BrainCells, Inc, Bristol-Myers Squibb Company, Cephalon, Clinical Trials Solutions, LLC, CNS Response, Compellis, Cypress Pharmaceuticals, Dov Pharmaceuticals, Eisai, Inc., Eli Lilly \& Company, EPIX Pharmaceuticals, Euthymics Bioscience, Inc., Fabre-Kramer, Pharmaceuticals, Inc., Forest Pharmaceuticals Inc., GlaxoSmithKline, GrunenthalGmBH, Janssen Pharmaceutica, Jazz Pharmaceuticals, J \& J Pharmaceuticals, Knoll Pharmaceutical Company, Labopharm, Lorex Pharmaceuticals, Lundbeck, MedAvante Inc., Merck, Methylation Sciences, Neuronetics, Novartis, Nutrition 21, Organon Inc., PamLab, LLC, Pfizer Inc, PharmaStar, Pharmavite, Precision Human Biolaboratory, Prexa Pharmaceuticals, Inc., PsychoGenics, Psylin Neurosciences, Inc., Ridge Diagnostics, Inc., Roche, Sanofi-Aventis, Sepracor, Schering-Plough, Solvay Pharmaceuticals, Inc., Somaxon, Somerset Pharmaceuticals, Synthelabo, Takeda, Tetragenex, TransForm Pharmaceuticals, Inc., Transcept Pharmaceuticals, Vanda Pharmaceuticals Inc, Wyeth-Ayerst Laboratories. He has received speaking and publishing honoraria from Adamed, Co., Advanced Meeting Partners, American Psychiatric Association, American Society of Clinical Psychopharmacology, Astra-Zeneca, Belvoir, Boehringer-Ingelheim, Bristol-Myers Squibb Company, Cephalon, Eli Lilly \& Company, Forest Pharmaceuticals Inc., GlaxoSmithKline, Imedex, Novartis, Organon Inc., Pfizer Inc, PharmaStar, MGH Psychiatry Academy/Primedia, MGH Psychiatry Academy/Reed-Elsevier, UBC, and Wyeth-Ayerst Laboratories. He holds equity in Compellis. He currently holds a patent for SPCD and a patent application for a combination of azapirones and bupropion in MDD, and has received copyright royalties for the MGH CPFQ, SFI, ATRQ, DESS, and SAFER diagnostic instruments. Dr. Mischoulon has received research support from the Bowman Family Foundation, BristolMyers Squibb Co., Cederroth, FisherWallace, Ganeden, LichtwerPharma, Nordic Naturals, Laxdale (Amarin), Methylation Sciences, Inc. (MSI), and SwissMedica. He has received honoraria for consulting, speaking, and writing from Pamlab, Bristol-Myers Squibb Co., Nordic Naturals, Virbac, Pfizer, Reed Medical Education, and the Massachusetts General Hospital Psychiatry Academy. He has received royalties from Back Bay Scientific for PMS Escape, and from Lippincott Williams \& Wilkins for published book "Natural Medications for Psychiatric Disorders: Considering the Alternatives." No payment has exceeded $\$ 10,000$.

\section{REFERENCES}

1. Ionescu DF, Niciu MJ, Mathews DC, Richards EM, Zarate CA Jr. Neurobiology of anxious depression: a review. Depress Anxiety 2013;30: 374-385.

2. Fava M, Alpert JE, Carmin CN, Wisniewski SR, Trivedi MH, Biggs $\mathrm{MM}$, et al. Clinical correlates and symptom patterns of anxious depression among patients with major depressive disorder in STAR*D. Psychol Med 2004;34:1299-1308.

3. Papakostas GI, Fan H, Tedeschini E. Severe and anxious depression: combining definitions of clinical sub-types to identify patients differentially responsive to selective serotonin reuptake inhibitors. Eur Neuropsychopharmacol 2012;22:347-355.

4. Altamura AC, Montresor C, Salvadori D, Mundo E. Does comorbid subthreshold anxiety affect clinical presentation and treatment response in depression? A preliminary 12-month naturalistic study. Int J Neuropsychopharmacol 2004;7:481-487.

5. Fava M, Rush AJ, Alpert JE, Carmin CN, Balasubramani GK, Wis- 
niewski SR, et al. What clinical and symptom features and comorbid disorders characterize outpatients with anxious major depressive disorder: a replication and extension. Can J Psychiatry 2006;51:823-835.

6. Maes M, Van der Planken M, Stevens WJ, Peeters D, DeClerck LS, Bridts $\mathrm{CH}$, et al. Leukocytosis, monocytosis and neutrophilia: hallmarks of severe depression. J Psychiatr Res 1992;26:125-134.

7. McAdams C, Leonard BE. Neutrophil and monocyte phagocytosis in depressed patients. Prog Neuropsychopharmacol Biol Psychiatry 1993; 17:971-984.

8. Avlund K, Hokland M, Mehlsen MY, Thomsen DK, Viidik A, Ekmann A, et al. Differential associations between white blood cell counts and fatigue in young and older adults. Aging Clin Exp Res 2012;24:439-447.

9. Miller AH, Maletic V, Raison CL. Inflammation and its discontents: the role of cytokines in the pathophysiology of major depression. Biol Psychiatry 2009;65:732-741.

10. Pasco JA, Nicholson GC, Williams LJ, Jacka FN, Henry MJ, Kotowicz MA, et al. Association of high-sensitivity C-reactive protein with de novo major depression. Br J Psychiatry 2010;197:372-377.

11. Reichenberg A, Yirmiya R, Schuld A, Kraus T, Haack M, Morag A, et al. Cytokine-associated emotional and cognitive disturbances in humans. Arch Gen Psychiatry 2001;58:445-452.

12. Berk M, Dean O, Drexhage H, McNeil JJ, Moylan S, O’Neil A, et al. Aspirin: a review of its neurobiological properties and therapeutic potential for mental illness. BMC Med 2013;11:74.

13. Hannestad J, DellaGioia N, Bloch M. The effect of antidepressant medication treatment on serum levels of inflammatory cytokines: a metaanalysis. Neuropsychopharmacology 2011;36:2452-2459.

14. Baek JH, Kang ES, Fava M, Mischoulon D, Nierenberg AA, Yu BH, et al. Serum lipids, recent suicide attempt and recent suicide status in patients with major depressive disorder. Prog Neuropsychopharmacol Biol Psychiatry 2014;51:113-118.

15. Sheehan DV, Lecrubier Y, Sheehan KH, Amorim P, Janavs J, Weiller E, et al. The Mini-International Neuropsychiatric Interview (M.I.N.I.): the development and validation of a structured diagnostic psychiatric interview for DSM-IV and ICD-10. J Clin Psychiatry 1998;59(Suppl 20):2233; quiz 34-57.

16. You SW, Kim YS, Noh JS, Oh KS, Kim CH, Namkoong K, et al. The validation study of the Korean version of Mini-Interational Neuropsychiatric Interview. Anxiety Mood 2006;2:50-55.

17. Hamilton M. Development of a rating scale for primary depressive ill- ness. Br J Soc Clin Psychol 1967;6:278-296.

18. Rao S, Zisook S. Anxious depression: clinical features and treatment. Curr Psychiatry Rep 2009;11:429-436.

19. Chirumbolo S. State-of-the-art review about basophil research in immunology and allergy: is the time right to treat these cells with the respect they deserve? Blood Transfus 2012;10:148-164.

20. Ohtsu H. Progress in allergy signal research on mast cells: the role of histamine in immunological and cardiovascular disease and the transporting system of histamine in the cell. J Pharmacol Sci 2008;106:347-353.

21. Senra MS, Wollenberg A. Psychodermatological aspects of atopic dermatitis. Br J Dermatol 2014;170(Suppl 1):38-43.

22. Di Marco F, Verga M, Santus P, Giovannelli F, Busatto P, Neri M, et al. Close correlation between anxiety, depression, and asthma control. Respir Med 2010;104:22-28.

23. Roth MK, Bingham B, Shah A, Joshi A, Frazer A, Strong R, et al. Effects of chronic plus acute prolonged stress on measures of coping style, anxiety, and evoked HPA-axis reactivity. Neuropharmacology 2012;63:11181126.

24. McCarty R, Horwatt K, Konarska M. Chronic stress and sympatheticadrenal medullary responsiveness. Soc Sci Med 1988;26:333-341.

25. Shahriari M, Hulskamp M, Schellmann S. Seeds of Arabidopsis plants expressing dominant-negative AtSKD1 under control of the GL2 promoter show a transparent testa phenotype and a mucilage defect. Plant Signal Behav 2010;5:1308-1310.

26. Toyoda M, Nakamura M, Makino T, Hino T, Kagoura M, Morohashi M. Nerve growth factor and substance $P$ are useful plasma markers of disease activity in atopic dermatitis. Br J Dermatol 2002;147:71-79.

27. Baldwin AL. Mast cell activation by stress. Methods Mol Biol 2006;315: 349-360.

28. Skaper SD, Giusti P, Facci L. Microglia and mast cells: two tracks on the road to neuroinflammation. FASEB J 2012;26:3103-3117.

29. Dere E, Zlomuzica A, De Souza Silva MA, Ruocco LA, Sadile AG, Huston JP. Neuronal histamine and the interplay of memory, reinforcement and emotions. Behav Brain Res 2010;215:209-220.

30. Goodnick PJ, Puig A, DeVane CL, Freund BV. Mirtazapine in major depression with comorbid generalized anxiety disorder. J Clin Psychiatry 1999;60:446-448.

31. Chikahisa S, Kodama T, Soya A, Sagawa Y, Ishimaru Y, Sei H, et al. Histamine from brain resident MAST cells promotes wakefulness and modulates behavioral states. PLoS One 2013;8:e78434. 